\title{
An update of SGLT1 and SGLT2 Inhibitors in early phase diabetes-type 2 clinical trials
}

\author{
Ernest Adeghate, Sahar Mohsin, Faisal Adi, Fares Ahmed, Ali Yahya, Huba \\ Kalász, Kornelia Tekes \& Ernest A. Adeghate
}

To cite this article: Ernest Adeghate, Sahar Mohsin, Faisal Adi, Fares Ahmed, Ali Yahya, Huba Kalász, Kornelia Tekes \& Ernest A. Adeghate (2019): An update of SGLT1 and SGLT2 Inhibitors in early phase diabetes-type 2 clinical trials, Expert Opinion on Investigational Drugs, DOI:

10.1080/13543784.2019.1655539

To link to this article: https://doi.org/10.1080/13543784.2019.1655539

Accepted author version posted online: 11 Aug 2019.

Submit your article to this journal $₫$

Шll Article views: 24

Q View related articles $\longleftarrow$

View Crossmark data ־ 
Publisher: Taylor \& Francis \& Informa UK Limited, trading as Taylor \& Francis Group

Journal: Expert Opinion on Investigational Drugs

DOI: $10.1080 / 13543784.2019 .1655539$

\section{An update of SGLT1 and SGLT2 Inhibitors in early phase diabetes-type 2 clinical trials}

Ernest Adeghate ${ }^{\$}$, Sahar Mohsin $^{2 \$}$, Faisal Adi $^{2}$, Fares Ahmed ${ }^{2}$, Ali Yahya ${ }^{2}$, Huba Kalász ${ }^{1}$, Kornelia Tekes $^{3}$ and Ernest A. Adeghate ${ }^{2}$

${ }^{1}$ Department of Pharmacology and Pharmacotherapy, Faculty of Medicine, Semmelweis University, Budapest, Hungary

${ }^{2}$ Department of Anatomy, College of Medicine \& Health Sciences, United Arab Emirates University, Al Ain, United Arab Emirates

${ }^{3}$ Department of Pharmacodynamics, Faculty of Pharmacy, Semmelweis University, Budapest, Hungary

$\$=$ the authors contributed equally

Corresponding author:

Professor Ernest A. Adeghate, MD, PhD

Department of Anatomy

College of Medicine \& Health Sciences

United Arab Emirates University

P.O. Box 17666, Al Ain

United Arab Emirates

e-mail: eadeghate@uaeu.ac.ae

\section{Abbreviations}

$\mathrm{aa}=$ Amino acid

$\mathrm{DM}=$ Diabetes mellitus

DPP-4 = Dipeptidyl peptidase 4 
eGFR = Estimated glomerular filtration rate

EMA $=$ European Medicines Agency

FDA $=$ Food and Drug Administration, United States

FTO $=$ Fat mass and obesity-associated gene

$\mathrm{GI}=$ Gastrointestinal tract

GIP $=$ Gastric inhibitory hormone

GLP-1 = Glucagon-like peptide 1

HbA1c = Glycated hemoglobin

IGF2BP = Insulin growth factor 2 mRNA-binding protein

IRS-1 = Insulin receptor substrate 1

PCT = Proximal convoluted tubules

PPAR $-\gamma 2=$ Peroxisome proliferator-activated receptor gamma 2

q.d. = Daily

SGLT1 = Sodium glucose co-transporter 1

SGLT2 = Sodium glucose co-transporter 2

T1DM = Type 1 diabetes mellitus

T2DM = Type 2 diabetes mellitus

TCF7L2 = Transcription factor-7-like 2

USA $=$ United States of America 


\begin{abstract}
Introduction: More than 424 million adults have diabetes mellitus (DM). This number is expected to increase to 626 million by 2045 . The majority (90-95\%) of people with DM has type 2-diabetes (T2DM). The continued prevalence of DM and associated complications has prompted investigators to find new therapies. One of the most recent additions to the antidiabetic armamentarium are inhibitors of sodium-glucose co-transporters 1 and 2 (SGLT1, SGLT2).

Areas covered: The authors review the status of SGLT2 inhibitors for the treatment of T2DM and place an emphasis on those agents in early phase clinical trials. Data and information were retrieved from American Diabetes Association, Diabetes UK, ClinicalTrials.gov, PubMed, and Scopus websites. The keywords used in the search were T2DM, SGLT1, SGLT2 and clinical trials.

Expert opinion: The benefits of SGLT inhibitors include reductions in serum glycated haemoglobin (HbA1c), body weight, blood pressure and cardiovascular and renal events. However, SGLT inhibitors increase the risk of genitourinary tract infections, diabetic ketoacidosis and bone fractures. The development of SGLT inhibitors with fewer side effects and as combination therapies are the key to maximizing the therapeutic effects of this important class of anti-diabetic drug.
\end{abstract}

Keywords: SGLT1, SGLT2 inhibitors, Type 2 Diabetes mellitus, Clinical trials 


\section{Article Highlights}

- Diabetes mellitus currently affects 424 million people globally

- Short and long-term complications of diabetes mellitus (DM) are still common in spite of the large pool of medications available to treat the disease

- SGLT1 and 2 inhibitors block the reabsorption of glucose from the intestinal mucosa and proximal convoluted tubules, respectively

- SGLT1 and 2 inhibitors cause significant reductions in body weight, blood pressure and HbA1c level

- SGLT2-induced reduction in cardiovascular and renal events in T2DM patients with well-established CVD and kidney disease, is an added advantage for this class of hypoglycemic agents

- Dual SGLT inhibitors with fewer side effects have great potential to succeed as a major addition to the anti-diabetic drugs armamentarium. 


\section{Introduction}

\subsection{Diabetes mellitus}

Diabetes mellitus (DM) is a chronic metabolic disease that affects more than 424 million adults worldwide [1]. This number is projected to increase to almost 627 million in the next 25 years [1]. Type $2 \mathrm{DM}$ is the most common variety and accounts for 90-95\% of all cases of DM [2]. T2DM is more prevalent in adults and older age groups. T2DM may be caused by a variety of factors including but not limited to defective insulin secretion, resistance to insulin, structural changes in insulin molecule, or anomaly in the configuration of GLUT4 receptor [3]. These anomalies may lead to chronic hyperglycemia. The severity of T2DM within and between ethnic groups may be due to mutations in or abnormal genes regulating glucose metabolism. These genes include: FTO, PPAR- $\gamma$ 2, IGF-2 binding protein, IRS-1, TCF7L2, and several others [4]. The multifactorial nature of the etiology and pathogenesis of T2DM makes it difficult to treat with monotherapy, posing a strong challenge to researchers and clinicians alike. The continued increase in the prevalence and complications associated with T2DM has arouses the urge to find new and more effective drugs to treat and prevent T2DM and its complications. Sodium-glucose co-transporters 1 and 2 inhibitors were discovered in the light of these efforts to find a more potent drug for the effective treatment of T2DM.

\subsection{History and discovery of SGLT1 and SGLT2}

The human SGLT1 is a 664-amino acid (aa) protein that is located on chromosome 22 at "q13.1" [5]. SGLT2 protein on the other hand is composed of 672 aa and is located on chromosome 16 at “p11.2” [6]. The discovery of SGLT went as far back as 1930s when Chasis et al [7] examined the role of phlorizin on human renal excretion of glucose. They observed that the glucose filtered 
by the glomerulus is reabsorbed by the proximal convoluted tubules (PCT), a phenomenon that prevents the release of glucose into urine in a normal, functioning kidney. Chasis et al [7] showed that phlorizin itself was capable of preventing the reabsorption of glucose from the PCT. The period was followed by several years of investigations on the cellular and molecular regulation of glucose reabsorption from the PCT and the small intestine using a variety of models including but not limited to preparations of intestinal microvilli membrane vesicles [8]. Additional studies reported that mutations of SGLT2 genes resulted in severe glycosuria [6]. Moreover, it was also observed that animals lacking the SGLT genes were unable to reabsorb glucose from the PCT [9]. All of these observations support the role of SGLT in the regulation of glucose reabsorption from the PCT (SGLT2) and the intestinal mucosa (SGLT1) to blood circulation. In the late 1980s, Ernest Wright and his co-workers cloned SGLT genes and concluded that SGLT1 is more predominant in the small intestine while SGLT2 is responsible for the reabsorption of glucose through the brush border of the renal PCT [10].

The cloning of the genes responsible for the reabsorption of glucose, especially from the renal PCT marked a turning point in SGLT biology and paved the way for intensive investigations as to what will happen to DM patients if these proteins (SGLTs) were inhibited. The rational behind this approach is that reduction of hyperglycemia, a major inducer of oxidative stress, will reduce some of the symptoms and complications associated with DM [11]. The first known inhibitor of SGLTs is phlorizin, a chalcone, first extracted from the bark of the roots of apple trees by De Koninck in 1835 [12]. The name of this bitter-tasting phlorizin is derived from the Greek word for "root" [13].

The early 1940s marked an important milestone in the history of SGLT inhibitors, when the molecular structure of phlorizin was determined after synthesis by Zempplen and Bognar [14]. 
They showed that phlorizin is a 2'-glucoside of phloretin, a flavonoid with antipyretic properties [13]. Although, von Mering has noted as far back as 1886, that phlorizin causes glycosuria [15], it was not until the 1980s that the mechanism by which SGLT reabsorbs glucose through brush borders epithelial cells was identified and characterized [16]. All of these efforts on the biology of SGLTs to find a role for it in the treatment of DM have led to the discovery of the first SGLT inhibitor in 2000 [17] and eventually the first specific SGLT2 inhibitor in 2008 [18]. Danagliflozin, the first gliflozin to be discovered, was approved for the treatment of T2DM in 2012 and 2014, respectively in Europe and the USA [19].

\section{Mechanisms of actions, benefits and adverse effects SGLT1 and 2 inhibitors}

\subsection{SGLT1 inhibitors}

SGLT1 inhibitors prevent the absorption of glucose from the microvilli of the enterocytes of the small intestine, and to a lesser extent from the brush border of the epithelial cells of renal PCT [6]. In contrast to SGLT2, SGLT1 is located in the apical plasma membrane of cells in many organs, including the S3 segment of the PCT, gastrointestinal tract, heart (capillary endothelium), and red blood cells, lung (alveolar and Clara or club cells), liver (biliary epithelium) [20, 21].

\subsection{SGLT2 inhibitors}

SGLT2 inhibitors block the reabsorption of glucose from the first segment (S1) of PCT. Since SGLT2 are also found on cells of the liver and the brain [22], they are able to potentially prevent the influx of glucose into these tissues. In contrast to SGLT1, SGLT2 prevents the reabsorption of more than $90 \%$ of glucose filtered through the glomerular basement membrane compared to about $10 \%$ for SGLT1. 
SGLT inhibitors, therefore, competitively block SGLT protein located on the apical surfaces of the cells of the renal PCT and intestinal mucosa, capillary endothelium of the myocardium, alveolar and club cells of the lung, and the biliary epithelium.

\subsection{Dual SGLT1-SGLT2 inhibitors}

Dual SGLT1-SGLT2 inhibitors, such as sotagliflozin and licogliflozin, are capable of preventing glucose uptake from the brush border of the columnar cells of the small intestine in addition to their ability to impede the absorption of glucose from the first, initial, segment (S1) of the PCT. This property of dual SGLT1-SGLT2 inhibitors adds another agonistic effect in the amelioration of hyperglycemia. The use of dual SGLT1-SGLT2 inhibitors comes with advantages and disadvantages. By also inhibiting SGLT1 (in addition to SGLT2), sotagliflozin, lowers the glucose upsurge seen immediately after a meal [23]. Sotagliflozin [23] and licogliflozin [24] also facilitates GLP-1 release from the L-cells of the GIT [23]. Advantages and disadvantages of dual SGLT1-SGLT2 inhibitors versus selective SGLT2 inhibitors include the following [23, 24, 25]:

\section{Advantages}

- Reduces postprandial glucose surge

- Increases GLP-1 release from the cecum

- Inhibits DPP-4, thereby prolonging the lifespan of GLP-1

- Could serve as adjuvant therapy in the treatment of Type 1 DM

\section{Disadvantages [26]}

- Causes adverse GIT effects like diarrhea

- Induces a higher rate of diabetic ketoacidosis

- Increases the risk of hypoglycemia 


\subsection{Advantages of SGLT1 and 2 inhibitors}

SGLT cause significant reductions in:

$\circ \quad$ blood glucose level

$\circ \mathrm{HbA1c}$

$\circ$ body weight

$\circ \quad$ blood pressure

$\circ \quad$ reduced triglycerides

Since these parameters are common co-morbidities in T2DM, reductions in all of them would reduce complications associated with DM [11]. Hyperglycemia is a major inducer of oxidative stress. It is well known that oxidative stress induces glycation of proteins, which in turn leads to malfunction of important enzymes in the body [11].

\subsection{Side effects of SGLT1 and 2 inhibitors}

- Polyuria - due to the osmotic nature of glucose retained in urine

- Infections of the urinary and genital tracts - because large quantity of glucose acts as a media for the growth of fungi in the urinary tract.

- Hypotension - This is not a major adverse effect of SGLT2 but hypotension may occur when combined with loop diuretics [27].

- Hypoglycemia - This may occur if SGLT2 inhibitors is combined with insulin or sulfonylureas

- Lower limb amputation - hypovolemia leading to blood viscosity, venous thromboembolism. This is probably not a class effect because a meta-analysis of 27 random controlled trials showed that although the risk of peripheral artery disease 
increased with SGLT2 inhibitors, it was only significant for patients taking canagliflozin $[28,29]$

○ Increased risk of bone fracture - calcium and phosphate ion imbalance? [30]

○ Acute kidney injury - Probably due to SGLT-induced disturbance in the regular and physiological function of the kidney and hypovolemia [30]

Other side effects reported for SGLT2 inhibitors include nausea, polydipsia, arthralgia, angioedema, perineal necrotizing fasciitis, Fournier gangrene, diabetic ketoacidosis and hyperkalemia [30, 31].

\section{SGLT1 and 2 inhibitors approved by the FDA and EMA}

\section{1. Dapagliflozin}

Dapagliflozin is a selective, FDA-approved, SGLT2 inhibitor for the treatment of T2DM in combination with regimens of diet, exercise and anti-diabetic drugs. Dapagliflozin, produced through a joint venture by Bristol-Myers Squibb and AstraZeneca, can be given per os at a dose of 5-10 mg per day [32]. Reports from DECLARE-TIMI 58, a randomized controlled study involving 17,160 T2DM patients with established cardiovascular disease (CVD) or risks of CVD, showed that danagliflozin treatment for four years resulted in significantly lower cardiovascular death rate. It also resulted in a reduced rate of heart failure related hospitalization [33]. Additional data from the DECLARE-TIMI 58 randomized trial also showed that danagliflozin can prevent and lower the progression of renal disease in T2DM patients with and without established kidney condition [34]. Fig 1, Table 1. 


\section{2. Canagliflozin}

Canagliflozin, developed by Johnson \& Johnson, USA, was approved in 2013 by the FDA (USA) for the treatment of T2DM. The CANVAS (Canagliflozin Cardiovascular Assessment Study), a large study spearheaded in Australia involving more than 10,000 patients who were given canagliflozin randomly versus placebo, showed a significantly lower risk of cardiovascular illness coupled with a marked reduction in the rate of hospitalization for heart and kidney failure $[35,36]$. This study lasted over four years, indicating that some of the long-term effects of canagliflozin were also in display. In a similar trend, CREDENCE, a recent randomized controlled study examining the effect of canagliflozin on cardiovascular and renal outcome in patients with T2DM, showed that this SGLT2 inhibitor improves cardiovascular (e.g. rate of heart failure hospitalization, non-fatal myocardial infarction etc.) and renal outcomes (e.g. kidney failure [37]. In a recently published double blind, randomized CREDENCE Trial, canagliflozin was reported to reduce the risk of cardiovascular and renal failure in T2DM subjects with renal disease [37, 38]. Canagliflozin can be prescribed for oral administration (100$300 \mathrm{mg}$ tablets). Fig 1, Table 1.

\subsection{Empagliflozin}

Empagliflozin, another strong inhibitor of SGLT2, is a product of a joint venture between Boehringer Ingelheim and Eli Lilly Pharmaceutical companies. In the EMPA-REG OUTCOME randomized controlled trial involving a large number $(>7,000)$ of patients, empagliflozin was reported to significantly reduce cardiovascular disease risks, three years after treatment [39]. Empagliflozin was approved for the treatment of T2DM and for the reduction of death from cardiovascular disease in 2014 and 2016, respectively [40]. Improvement in cardiovascular 
profile may be due to the fact that empagliflozin increased HDL level and reduced blood triglyceride concentration as reported in a more recent EMPA-REG OUTCOME Study [41]. Indeed, another recent study shows that empagliflozin can reduce cardiovascular death risks by as much as 38\% [42] and delay the progression of chronic kidney disease in T2DM patients with or without cardiac failure [43]. This shows that empagliflozin has cardio-renoprotective effect similar to that of dapagliflozin and canagliflozin, indication that this is most likely a class effect. Empagliflozin is given per os at 10 or $25 \mathrm{mg}$ q.d. Fig 1, Table 1.

\subsection{Ertugliflozin}

In a clinical trial involving more than 400 patients, ertugliflozin was reported to significantly reduce fasting plasma glucose, blood pressure and total body weight, 26 weeks after the administration of ertugliflozin when compared placebo, It was of particularly interesting to note that ertugliflozin was safe in patients with chronic renal disease. Moreover, hypoglycemia and infections of the urinary and genital tracts were not markedly different between treated and placebo groups [44]. However, the volume deficit that was observed in ertugliflozin-treated group [44] was higher relative to placebo. The recommended daily dose of ertugliflozin is 5-15 mg. VERTIS MONO Trial, however, showed that the rate of fungal infection of the genitalia was significantly higher in patients taking ertugliflozin when compared to placebo [45]. A randomized, double blind, placebo-controlled interventional clinical trial (VERTIS-CV) conducted to examine the effectiveness and safety of ertugliflozin on cardiovascular outcomes in a pool of T2DM 8,000 patients is currently ongoing and will be completed in December 2019, after six years of intensive study [46, 47]. Ertugliflozin, approved by the FDA on December 22, 2017, can be taken orally at a daily dosage of 5-15 mg. Fig 1 , Table 1. 


\section{SGLT 1 and 2 inhibitors under investigation (not approved by the FDA and EMA)}

\subsection{Ipragliflozin}

Ipragliflozin was the first SGLT2 inhibitor approved for the treatment of T2DM in Japan in 2014. It was produced by a joint venture between Astellas Pharma and Kotobuki Pharmaceutical in Japan. In a large Japanese, post-marketing open study, examining the effect of ipragliflozin in more than 8,000 patients, it was reported that this drug has similar efficacy when compared to currently available SGLT2 inhibitors. The investigators showed that ipragliflozin could significantly reduce blood glucose level, body weight, HbAlc, blood pressure, and even LDLcholesterol. The side effects recorded for this drug are similar to those of SGLT2 inhibitors in the market and include renal and urinary tract infections [48]. Ipragloflozin has not received the approval of the FDA in the USA $[49,50]$. Ipragliflozin is given orally as $50 \mathrm{mg}$ once daily. Fig 2A, Table 2 .

\subsection{Tofogliflozin}

Tofogliflozin is a product of Chugai Pharmaceutical Company, Japan. It was developed in conjunction with Sanofi-Aventis and Kowa Pharmaceuticals and approved for the treatment of T2DM in 2014 in Japan. In a large post-marketing open study involving more than 6,897 patients, tofogliflozin was reported to markedly reduce HbA1c and bodyweight. In addition to the beneficial effects of tofogliflozin, polyuria, increased risk infections of the urinary and genital tracts was also observed [51]. The FDA has not yet approved tofogliflozin, and it is therefore still considered an investigational drug in the USA. The recommended dose of tofogliflozin is $20 \mathrm{mg}$ per os, once in a day. Fig 2A, Table 2. 


\subsection{Sotagliflozin}

Sotagliflozin is product of Sanofi and Lexicon Pharmaceuticals and it is currently under consideration for the treatment of T1DM by the European Medicines Agency [52]. Sotagliflozin inhibits both SGLT1 and SGLT2 in the kidney and the intestine leading to a marked reduction in HbA1c, body weight, blood pressure, and post-prandial blood glucose. The role of sotagliflozin is currently being explored in several clinical trials $[53,54,55]$. A recent meta-analysis of randomized control trials showed that sotagliflozin increased the rate of diabetic ketoacidosis when compared to placebo but the rate of UTI did not significantly differ when compared to control [56]. This indicates that dual SGLT inhibitors may cause fewer infections associated with the urinary tract. The recommended daily dose of sotagliflozin is $200 \mathrm{mg}$ q.d., but could be increased to $400 \mathrm{mg}$ if a more stringent glycemic control is required [53]. Fig 2A, Table 2.

\subsection{Luseogliflozin}

Luseogliflozin, when administered at $2.5 \mathrm{mg}$ q.d. for a year to a cohort of $37 \mathrm{~T} 2 \mathrm{DM}$ patients in Japan (LIGHT Study), caused large reductions in fasting blood glucose level, HbA1c, body weight, triglycerides and blood pressure (systolic and diastolic). However, the blood concentration of ketone bodies was increased over the same period [57]. Reports from LEAD Trial showed that luseogliflozin, administered for 8 months, caused a marked reduction in the lipid content of liver of patients suffering from non-alcoholic fatty liver disease [58]. Although luseogliflozin has been marketed since 2014 in Japan for the treatment of T2DM, it has not 
received the approval by the FDA [59]. The recommended dosage for luseogliflozin is 5 mg q.d. but it effect may be less effective in severe renal failure [60]. Fig 2A, Table 2.

\subsection{Remogliflozin}

Remogliflozin etaborate is a pro-drug of remogliflozin, a selective inhibitor of SGLT2 protein. It prevents the reabsorption of glucose from the epithelium of the PCT. It is a drug developed by Avolynt Inc (Research Triangle Park, North Carolina, USA). Remogliflozin is currently undergoing clinical trials for the treatment of T2DM and non-alcoholic steatohepatitis. Remogliflozin has been reported to reduce blood glucose and HbA1c levels [61]. The phase 2b trial was completed in 2018 [62]. It is well tolerated but with a relatively short half-life of just 2$4 \mathrm{~h}[63,64]$. In contrast to the advantages of remogliflozin, it also causes side effects (e.g. urinary and genital tract fungal infections, syncope) [65] that are similar to those seen with other SGLT2 inhibitors. Although remogliflozin was approved for the treatment of T2DM in India in July 2019, it is not yet licensed for use in the USA. The daily dosage of remogliflozin $200 \mathrm{mg}$ is two doses [64]. Fig 2A, Table 2

\subsection{Velagliflozin}

This SGLT2 inhibitor was developed by Boeringer Ingelheim (Germany) and currently used on veterinary subjects. It was concluded that $0.3 \mathrm{mg} / \mathrm{kg}$ body weight of velagliflozin per os for 16 weeks to ponies was safe to use [66]. It is unknown whether velagliflozin could eventually be of use in humans. Fig 2B, Table 2.

\subsection{Henagliflozin}


In a study that examined the effect of henagliflozin on T2DM, it was reported that this SGLT2 inhibitor reduced plasma glucose level in a dose-dependent manner. No severe side effects were reported for this small group of T2DM patients with doses ranging from 5 - $20 \mathrm{mg}$ per day [67]. The authors suggested that henagliflozin is suitable for, once daily, regimen [67]. Due to the small number of patients in this study it is likely premature to rule out adverse effects that are related to SGLT2 inhibitors in general. Two phase III clinical trials conducted by Hengrui Medicine Co (Jiangsu, China) that examine the impact of henagliflozin on T2DM is currently ongoing in China [68]. Fig 2B, Table 2.

\subsection{Bexagliflozin}

Bexagliflozin, like most of the SGLT2 inhibitors, is a phenolic glycoside. More than 10 clinical trials have been completed on the effect of bexagliflozin on the treatment of T2DM. One of the few published results includes a small study presented at the Meeting of the American Society for Nephrology, Kidney Week in San Diego in October 2018. In a study that examined 312 patients suffering from T2DM and end stage kidney disease, bexagliflozin, was reported to significantly reduce $\mathrm{HbAlc}$ level, body weight, and blood pressure in addition to its glucose lowering effects. In a more recent report, $20 \mathrm{mg} /$ day of bexagliflozin, administered over a 96week period, was well tolerated and induced significant reduction in blood pressure, weight loss and HbA1c level [69]. Fig 2B, Table 2.

TABLE 2 HERE

\subsection{Licogliflozin}

Licogliflozin is a dual SGLT (1 and 2) inhibitor, currently under development by Norvatis Institute of Medical Research (Basel, Switzerland). In a recent report of open clinical study, it was shown that $150 \mathrm{mg}$ q.d. licogliflozin, when administered to 88 patients in 6 divided doses for 
12 weeks, lowers postprandial glucose spike, and weight. In addition, licogliflozin is safe, well tolerated and was able to improve metabolic parameters and incretin (GLP-1, GIP) levels. However, adverse effects (diarrhea, loose stools) associated with SGLT1 inhibitors were significantly more profound compared to placebo [24]. He et al [24] concluded that licogliflozin appears to be more effective than sotogliflozin, another dual SGLT inhibitor in the maintenance of glycemic control because licogliflozin can completely block SGLT1 when given in high doses (300 mg q.d). Fig 2B, Table 2.

\section{Conclusion}

Despite advanced technology, current knowledge and the many medications available to the population, the number of people with diabetes mellitus (DM) continues to rise. In addition to the increased prevalence, the associated complications of DM continue to take its toll on the quality of life of the patients and place an even a greater burden on the healthcare system. The introduction of SGLT2 inhibitors into the arsenal of anti-diabetic drugs available is a response to these challenges. The major advantage of SGLT2 inhibitors includes their ability to significantly reduce hyperglycaemia, body weight and blood pressure. These reductions, including SGLT2induced volume depletion, contribute to the lowering of cardiovascular and renal risks.

\section{Expert Opinion}

The ability of SGLT1 and 2 inhibitors to significantly reduce hyperglycemia, HbA1c, body weight, and blood pressure is a major advantage over many other classes of anti-diabetic drugs. This is because these parameters are known to cause a myriad of diseases including 
cardiovascular events, cancer and many others. SGLT2 inhibitors specifically prevent the reabsorption of glucose from PCT, thereby reducing hyperglycemia. Hyperglycemia is known to induce oxidative stress [11]. Oxidative stress in turn results in a cascade of events leading to the production of reactive oxygen species and formation of advanced glycated end products and several other molecular mechanisms that will cause long-term complications [11].

In contrast to the benefits of SGLT2 inhibitors, there are many adverse effects associated with this group of anti-diabetic drugs. SGLT2 inhibitors have been reported to cause polyuria, increase the risk of urinary and genital tract infections, hypotension, hypoglycemia, increased level of LDL-cholesterol [41], lower limb amputation (with canagliflozin), increase predisposition to developing bone fractures [29]. Other adverse effects associated with the use of SGLT2 inhibitors include nausea, polydipsia, arthralgia, angioedema, perineal necrotizing fasciitis, and diabetic ketoacidosis [41].

These adverse effects attributed to the intake of SGLT2 inhibitors are too many to ignore and attempts should made to generate an ideal SGLT2 inhibitor devoid of these severe side effects. In spite of these shortcomings, however, the major advantage of SGLT2 inhibitors is that they are relatively safe to use [70]. Moreover, several randomized control trials, such as, DECLARETIMI 58 [33], CANVAS [36], EMPA-REG OUTCOME [41-43], VERITAS [47] have all shown that SGLT2 inhibitors have cardio-reno-protective properties. In fact, it has been shown that SGLT2 inhibitors are more effective than GLP-1 receptor antagonists, in the prevention of hospitalization for cardiac failure and progression of renal disease [71]. 
The beneficial effects of SGLT2 inhibitors, which are indeed remarkable regarding the overall well being of the patients, can therefore be maximized.

Possible ways of mitigating the severity of these adverse effects could include the following:

(a) Development of newer, more potent and more specific generations of SGLT1 and 2 inhibitors.

- Several attempts have been made to develop new SGLT 1 and 2 inhibitors with lower rate of adverse effect that the current ones. A combined inhibition of SGLT1 and 2, with dual SGLT inhibitors may help in the reduction of SGLT2-induced adverse effects, such as urinary tract infection [41], hypotension (in patients taking loop diuretics) [27], increased risk of bone fracture [30]. Unfortunately, dual SGLT2 inhibitors cause significant increases in the number of diarrhea, diabetic acidosis and hypoglycemic events [26]. A reduction in the dosage could probably reduce these side effects, since dual SGLT inhibitors have been shown to also inhibit DPP-4 and stimulate incretins, such as GIP and GLP-1 [24-25]. Inhibition of DPP-4 increases the lifespan of GLP-1, which in turn reduces hyperglycemia by stimulating insulin release $[72,73]$.

\section{(b) Combination with existing drugs}

The combination of SGLT1 and 2 inhibitors with existing anti-diabetic medications, such as metformin, GLP-1 agonists, sulfonylureas and many others, has been generated by several pharmaceutical companies. The combination of SGLT2 inhibitors and other antidiabetic drugs will facilitate agonistic mechanisms and can help in the reduction of the effective therapeutic dose. In fact, a side effect could be completely eliminated if the dose 
could be reduced to the bare minimum needed to elicit the required beneficial effect. Li et al [74], in their review of six randomized clinical trials, showed that a combination of metformin and SGLT2 inhibitor is significantly more effective than other, non-SGLT2 inhibitor combinations. SGLT2 inhibitors when combined with GLP-1 receptor agonists have been reported to be more potent in the reduction of $\mathrm{HbA1c}$, glucose level, body weight and blood pressure than when each of the drugs were given alone [55].

\section{Funding}

The research of the authors is funded by College of Medicine and Health Sciences, United Arab Emirates Universityn31M374

\section{Declaration of interest}

The authors have no relevant affiliations or financial involvement with any organization or entity with a financial interest in or financial conflict with the subject matter or materials discussed in the manuscript. This includes employment, consultancies, honoraria, stock ownership or options, expert testimony, grants or patents received or pending, or royalties.

\section{Reviewer disclosures}

Peer reviewers on this manuscript have no relevant financial or other relationships to disclose

\section{References}

Papers of special note have been highlighted as either of interest $(\bullet)$ or of considerable interest $(\bullet)$ to readers

1. Diabetes Atlas. International Diabetes Federation, 8th Edition, 2017

2. American Diabetes Association. Classification and Diagnosis of Diabetes. Diabetes Care 2015; 38(Supplement 1): S8-S16. 
3. Adeghate E, Schattner P, Dunn E. An update on the etiology and epidemiology of diabetes mellitus. Ann NY Acad Sci. 2006; 1084: 1-29.

**A comprehensive review on the epidemiology of diabetes mellitus

4. Ali O. Genetics of type 2 diabetes. World J Diabetes 2013; 4: 114-123.

5. Hediger MA, Turk E, Wright EM. Homology of the human intestinal Na+/glucose and Escherichia coli Na+/proline cotransporters. Proc Natl Acad Sci USA 1989; 86:5748-5752.

6. Ghezzi C, Loo DDF, Wright EM. Physiology of renal glucose handling via SGLT1, SGLT2 and GLUT2. Diabetologia 2018; 61: 2087-2097

*A comprehensive review of the physiology of SLGTS

7. Chasis H, Jolliffe N, Smith HW. The action of phlorizin on the excretion of glucose, xylose, sucrose, creatinine and urea by man. J Clin Invest 1933; 12:1083-1090.

*An excellent expose of the history of SLGTs

8. Hopfer U, Nelson K, Perrotto J, et al. Glucose transport in isolated brush border membrane from rat small intestine. J Biol Chem 1973, 248:25-32

9. Sala-Rabanal M, Hirayama BA, Ghezzi C et al. Revisiting the physiological roles of SGLTs and GLUTs using positron emission tomography in mice. J Physiol 2016; 594:4425-4438.

10. Hediger MA, Coady MJ, Ikeda TS, et al. Expression cloning and cDNA sequencing of the $\mathrm{Na} /$ glucose co-transporter. Nature 1987; 330:379-381

11. Lotfy M, Adeghate J, Kalasz H, et al. Chronic Complications of Diabetes Mellitus: A Mini Review. Curr Diabetes Rev 2017; 13: 3-10.

*A comprehensive review on diabetes complications

12. De Koninck L. About the phloridzin (phlorrhizin). Annals of the Pharmacie 1835; 15: 7577.

13. Blaschek W. Natural Products as Lead Compounds for Sodium Glucose Cotransporter (SGLT) Inhibitors. Planta Med 2017; 83: 985-993

14. Zemplen G, Bognar R. Synthese des natürlichen Phlorrhizins. Chem Ber 1942; 75: 1040

15. Von Mering J. Über künstlichen Diabetes. Centralbl Med Wiss 1886; 22: 531

16. Lee WS, Wells RG, Hediger MA. The high affinity Na/glucose cotransporter: reevaluation and distribution of expression. J Biol Chem 1994; 268: 12032-12039 
17. Link JT, Sorensen BK. A method for preparing C-glycosides related to phlorizin. Tetrahedron Lett 2000; 41: 9213-9217

18. Meng W, Ellsworth BA, Nirschl AA, et al. Discovery of dapagliflozin: A potent, selective renal sodium-dependent glucose cotransporter 2 (SGLT2) inhibitor for the treatment of type 2 diabetes. J Med Chem 2008; 51: 1145-1149

19. Jung CH, Jang JE, Park JY. A Novel Therapeutic Agent for Type 2 Diabetes Mellitus: SGLT2 Inhibitor. Diabetes Metab J 2014; 38:261-273.

20. Kurosaki E, Ogasawara H. Ipragliflozin and other sodium-glucose cotransporter-2 (SGLT2) inhibitors in the treatment of type 2 diabetes: preclinical and clinical data. Pharmacol Ther 2013; 139:51-59.

21. Vrhovac I, Balen Eror D, Klessen D et al. Localizations of Na(+)-D-glucose cotransporters SGLT1 and SGLT2 in human kidney and of SGLT1 in human small intestine, liver, lung, and heart. Pflugers Arch 2015; 467:1881-1898.

22. Abdul-Ghani MA, Norton L, DeFronzo RA. Role of Sodium-Glucose Cotransporter 2 (SGLT 2) Inhibitors in the Treatment of Type 2 Diabetes. Endocr Rev 2011; 32: 515-531 **A comprehensive review of the effects of SGLT2 inhibitors in diabetes

23. Cariou B, Charbonnel B. Sotagliflozin as a potential treatment for type 2 diabetes mellitus. Expert Opin Investig Drugs 2015; 24:1647-1656.

24. He YL, Haynes W, Meyers CD, et al. The effects of licogliflozin, a dual SGLT1/2 inhibitor, on body weight in obese patients with or without diabetes. Diabetes Obes Metab. $2019 ; 21: 1311-1321$.

25. Cefalo CMA, Cinti F, Moffa S, et al. Sotagliflozin, the first dual SGLT inhibitor: current outlook and perspectives. Cardiovasc Diabetol. 2019; 18: 20.

26. Garg SK, Henry RR, Banks P, et al. Effects of Sotagliflozin Added to Insulin in Patients with Type 1 Diabetes. N Engl J Med. 2017; 377: 2337-2348

27. Johnsson K, Johnsson E, Mansfield TA, et al. Osmotic diuresis with SGLT2 inhibition: analysis of events related to volume reduction in dapagliflozin clinical trials. Postgrad Med. 2016;128: 346-355.

28. Kmietowicz Z. SGLT2 inhibitors for diabetes are linked to increased risk of lower limb amputation. BMJ 2018;363:k4828 
29. Dicembrini I, Tomberli B, Nreu B, et al. Peripheral artery disease and amputations with Sodium-Glucose co-Transporter-2 (SGLT-2) inhibitors: A meta-analysis of randomized controlled trials. Diabetes Res Clin Pract. 2019; 153:138-144.

30. Beitelshees AL, Leslie BR, Taylor SI. Sodium-Glucose Cotransporter 2 Inhibitors: A Case Study in Translational Research. Diabetes 2019; 68:1109-1120.

31. Bersoff-Matcha SJ, Chamberlain C, Cao C, et al. Fournier Gangrene Associated With Sodium-Glucose Cotransporter-2 Inhibitors: A Review of Spontaneous Post-marketing Cases. Ann Intern Med. 2019 May 7. doi: 10.7326/M19-0085. [Epub ahead of print]

32. Kasichayanula S, Liu X, Lacreta F et al. Clinical pharmacokinetics and pharmacodynamics of dapagliflozin, a selective inhibitor of sodium-glucose co-transporter type 2. Clin Pharmacokinet 2014; 53:17-27.

33. Wiviott SD, Raz I, Bonaca MP, et al. Dapagliflozin and Cardiovascular Outcomes in Type 2 Diabetes. N Engl J Med. 2019; 380: 347-357.

34. Mosenzon O, Wiviott SD, Cahn A, et al. Effects of dapagliflozin on development and progression of kidney disease in patients with type 2 diabetes: an analysis from the DECLARE-TIMI 58 randomised trial. Lancet Diabetes Endocrinol 2019; pii: S2213-8587 (19)30180-9.

35. Neal B, Perkovic V, Mahaffey KW et al. Canagliflozin and Cardiovascular and Renal Events in Type 2 Diabetes. N Engl J Med 2017; 377:644-657

**A large study on the effects of SGLT2 in cardiovascular and renal conditions

36. Mahaffey KW, Neal B, Perkovic V, et al. Canagliflozin for Primary and Secondary Prevention of Cardiovascular Events: Results From the CANVAS Program (Canagliflozin Cardiovascular Assessment Study). Circulation. 2018;137:323-334.

37. Mahaffey KW, Jardine MJ, Bompoint S, et al. Canagliflozin and Cardiovascular and Renal Outcomes in Type 2 Diabetes and Chronic Kidney Disease in Primary and Secondary Cardiovascular Prevention Groups: Results from the Randomized CREDENCE Trial. Circulation. 2019 Jul 11. doi: 10.1161/CIRCULATIONAHA.119.042007. [Epub ahead of print]

38. Perkovic V, Jardine MJ, Neal B, et al. Canagliflozin and Renal Outcomes in Type 2 Diabetes and Nephropathy. N Engl J Med. 2019; 380(24): 2295-2306.

39. Zinman B, Wanner C, Lachin JM, et al. Empagliflozin, Cardiovascular Outcomes, and Mortality in Type 2 Diabetes. N Engl J Med 2015; 373:2117-2128. 
40. Sizar O, Talati R. Empagliflozin. SourceStatPearls [Internet]. Treasure Island (FL): StatPearls Publishing; 2019 Jan 16.

41. Abdul-Ghani M, Del Prato S, Chilton R, et al. SGLT2 Inhibitors and Cardiovascular Risk: Lessons Learned From the EMPA-REG OUTCOME Study. Diabetes Care. 2016; 39: 717725 .

42. Fitchett D, Inzucchi SE, Lachin JM, et al. Cardiovascular Mortality Reduction With Empagliflozin in Patients With Type 2 Diabetes and Cardiovascular Disease. J Am Coll Cardiol. 2018;71: 364-367.

43. Butler J, Zannad F, Fitchett D, et al. Empagliflozin improves kidney outcomes in patients with or without heart failure. Circ Heart Fail. 2019;12: e005875.

44. Grunberger G, Camp S, Johnson J et al. Ertugliflozin in Patients with Stage 3 Chronic Kidney Disease and Type 2 Diabetes Mellitus: The VERTIS RENAL Randomized Study. Diabetes Ther 2018; 9: 49-66.

45. Aronson R, Frias J, Goldman A, et al. Long-term efficacy and safety of ertugliflozin monotherapy in patients with inadequately controlled T2DM despite diet and exercise: VERTIS MONO extension study. Diabetes Obes Metab. 2018; 20:1453-1460.

46. https://clinicaltrials.gov/ct2/show/NCT01986881?term=Ertugliflozin\&rank=7 (Assessed on July 18, 2019

47. Cannon CP, McGuire DK, Pratley R, et al. Design and baseline characteristics of the eValuation of ERTugliflozin efflcacy and Safety CardioVascular outcomes trial (VERTISCV). Am Heart J. 2018; 206:11-23.

48. Nakamura I, Maegawa H, Tobe $\mathrm{K}$ et al. Safety and efficacy of ipragliflozin in Japanese patients with type 2 diabetes in real-world clinical practice: interim results of the STELLALONG TERM post-marketing surveillance study. Expert Opin Pharmacother 2018;19:189201.

49. Veltkamp SA, Kadokura T, Krauwinkel WJ, et al. Effect of Ipragliflozin (ASP1941), a novel selective sodium-dependent glucose co-transporter 2 inhibitor, on urinary glucose excretion in healthy subjects. Clin Drug Investig 2011; 31:839-851

50. Ohkura T. Ipragliflozin: A novel sodium-glucose co-transporter 2 inhibitor developed in Japan. World J Diabetes 2015; 6: 136-144.

51. Utsunomiya K, Senda M, Kakiuchi S et al. Safety and efficacy of tofogliflozin in Japanese patients with type 2 diabetes mellitus in real-world clinical practice: Results of 3-month 
interim analysis of a long-term post-marketing surveillance study (J-STEP/LT). J Diabetes Investig. 2019 Jan 31. doi: 10.1111/jdi.13017. [Epub ahead of print]

52. Danni T, Cariou B, Buse JB et al. Improved Time in Range and Glycemic Variability With Sotagliflozin in Combination With Insulin in Adults With Type 1 Diabetes: A Pooled Analysis of 24-Week Continuous Glucose Monitoring Data From the in Tandem Program. Diabetes Care. 2019 Mar 4. pii: dc182149. doi: 10.2337/dc18-2149. [Epub ahead of print]

\section{**A comprehensive survey of the effects of combined Insulin-SGLT2 inhibitors in type 1 diabetes}

53. Cefalo CMA, Cinti F, Moffa S et al. Sotagliflozin, the first dual SGLT inhibitor: current outlook and perspectives. Cardiovasc Diabetol 2019;18:20.

54. https://www.diabetes.co.uk/news/2018/mar/sotagliflozin-accepted-by-ema-for-review-intreating-people-with-type-1-diabetes-97785339.html \{accessed March 15, 2019]

55. Rendell MS. Efficacy and safety of sotagliflozin in treating diabetes type 1. Expert Opin Pharmacother 2018; 19:307-315.

56. Musso G, Gambino R, professor, Cassader M, et al. Efficacy and safety of dual SGLT 1/2 inhibitor sotagliflozin in type 1 diabetes: meta-analysis of randomised controlled trials. BMJ. 2019; 365: 11328.

57. Sasaki T, Sugawara M, Fukuda M. Sodium-glucose cotransporter 2 inhibitor-induced changes in body composition and simultaneous changes in metabolic profile: 52-week prospective LIGHT (Luseogliflozin: the Components of Weight Loss in Japanese Patients with Type 2 Diabetes Mellitus) Study. J Diabetes Investig. 2019;10:108-117.

58. Sumida Y, Murotani K, Saito M, et al. Effect of luseogliflozin on hepatic fat content in type 2 diabetes patients with non-alcoholic fatty liver disease: A prospective, single-arm trial (LEAD trial). Hepatol Res. 2019;49:64-71.

59. Markham A, Elkinson S. Luseogliflozin: first global approval. Drugs. 2014; 74: 945-950.

60. Samukawa Y, Haneda M, Seino Y et al. Pharmacokinetics and Pharmacodynamics of Luseogliflozin, a Selective SGLT2 Inhibitor, in Japanese Patients With Type 2 Diabetes With Mild to Severe Renal Impairment. Clin Pharmacol Drug Dev. 2018; 7: 820-828.

61. Dash RP, Babu RJ, Srinivas NR. Comparative pharmacokinetics of three SGLT-2 inhibitors sergliflozin, remogliflozin and ertugliflozin: an overview. Xenobiotica 2017; 47: 1015-1026. 
62. https://finance.yahoo.com/news/avolynt-announces-completion-phase-2b-143600142.html (accessed on 16 march 2019)

63. Markham A. Remogliflozin Etabonate: First Global Approval. Drugs. 2019;79:1157-1161.

64. https://www.prnewswire.com/in/news-releases/glenmark-launches-novel-globally-researchedanti-diabetes-drug-remogliflozin-in-india-806614073.html. Accessed on July 18, 2019.

65. Mikhail N. Remogliflozin etabonate: a novel SGLT2 inhibitor for treatment of diabetes mellitus. Expert Opin Investig Drugs 2015; 24:1381-1387.

66. Meier A, de Laat M, Reiche D et al. The efficacy and safety of velagliflozin over 16 weeks as a treatment for insulin dysregulation in ponies. BMC Veterinary Res 2019;15:65

67. Yong X, Wen A, Liu X et al. Pharmacokinetics and Pharmacodynamics of Henagliflozin, a Sodium Glucose Co-Transporter 2 Inhibitor, in Chinese Patients with Type 2 Diabetes Mellitus. Clin Drug Investig 2016; 36:195-202.

68. http://www.hrs.com.cn/hren/products_pipeline_metabolics.html

69. Halvorsen YD, Walford GA, Massaro J, et al. A 96-Week Multinational Randomized Double-Blind Parallel-Group Clinical Trial Evaluating the Safety and Effectiveness of Bexagliflozin as a Monotherapy for Adults with Type 2 Diabetes. Diabetes Obes Metab. 2019 Jul 12. doi: 10.1111/dom.13833. [Epub ahead of print]

70. Scheen AJ. An update on the safety of SGLT2 inhibitors. Expert Opin Drug Saf. 2019; 18: 295-311.

71. Zelniker TA, Wiviott SD, Raz I, et al. Comparison of the Effects of Glucagon-Like Peptide Receptor Agonists and Sodium-Glucose Cotransporter 2 Inhibitors for Prevention of Major Adverse Cardiovascular and Renal Outcomes in Type 2 Diabetes Mellitus. Circulation. 2019;139: 2022-2031.

72. Lotfy M, Singh J, Kalász H, et al. Medicinal Chemistry and Applications of Incretins and DPP-4 Inhibitors in the Treatment of Type 2 Diabetes Mellitus. Open Med Chem J. 2011; 5(Suppl 2): 82-92.

73. Lotfy M, Singh J, Kalász H, et al. Medicinal Chemistry and Applications of Incretins and DPP-4 Inhibitors in the Treatment of Type 2 Diabetes Mellitus. Open Med Chem J. 2011; 5(Suppl 2):82-92. 
74. Li J, Gong Y, Li C, et al. Long-term efficacy and safety of sodium-glucose cotransporter2 inhibitors as add-on to metformin treatment in the management of type 2 diabetes mellitus: A meta-analysis. Medicine (Baltimore) 2017; 96:e7201.

75. Busch RS, Kane MP. Combination SGLT2 inhibitor and GLP-1 receptor agonist therapy: a complementary approach to the treatment of type 2 diabetes. Postgrad Med 2017; 129:686-697.

** Excellent article on the advantages of SGLT2 inhibitor and GLP-1 receptor agonist combination therapy

Table 1: List of SGLT 1 and 2 inhibitors that are currently approved by the FDA and EMA

\begin{tabular}{|c|c|c|c|c|c|c|}
\hline Generic name & Pharmacodynamics & $\begin{array}{l}\text { Primary } \\
\text { metabolite (s) }\end{array}$ & Half life & $\begin{array}{l}\text { Dosage } \\
\text { (mg) }\end{array}$ & $\begin{array}{l}\text { Main } \\
\text { Target }\end{array}$ & Ref \\
\hline Dapą & $\begin{array}{l}10 \mathrm{mg} / \text { day results in } \\
\text { excretion of } 70 \mathrm{~g} \\
\text { glucose }\end{array}$ & $\begin{array}{l}\text { Dapagliflozin 3- } \\
\text { O-glucuronide }\end{array}$ & $\begin{array}{l}13.8 \mathrm{~h} \text { at } 50 \\
\mathrm{mg} \text { dose }\end{array}$ & $\begin{array}{l}5,10, \\
\text { per os }\end{array}$ & SGLT2 & $\begin{array}{l}32- \\
34\end{array}$ \\
\hline Canas & $\begin{array}{l}100 \mathrm{mg} \text { caused } \\
\text { excretion of } 120 \mathrm{~g} \\
\text { glucose }\end{array}$ & $\begin{array}{l}\text { Canagliflozin 3- } \\
\text { O-glucuronide }\end{array}$ & $\begin{array}{l}13 \mathrm{~h} \text { at } 300 \\
\mathrm{mg} \text { dose }\end{array}$ & $\begin{array}{l}100- \\
300 \text { per } \\
\text { os }\end{array}$ & GLT2 & $\begin{array}{l}35- \\
38\end{array}$ \\
\hline Empagliflozin & $\begin{array}{l}25 \mathrm{mg} / \text { day induced } \\
93 \mathrm{~g} \text { of glucose } \\
\text { excretion }\end{array}$ & $\begin{array}{l}\text { Empagliflozin- } \\
\text { 2-O, 3-O-, and } \\
6-0- \\
\text { glucuronide. }\end{array}$ & $\begin{array}{l}12 \mathrm{~h} \text { at } 25 \mathrm{mg} \\
\text { dose }\end{array}$ & $\begin{array}{l}10,25, \\
\text { per os }\end{array}$ & SGLT2 & $\begin{array}{l}39- \\
43\end{array}$ \\
\hline Ertugliflozin & $\begin{array}{l}15 \mathrm{mg} / \text { day induced } \\
34 \mathrm{~g} \text { of glucose } \\
\text { excretion }\end{array}$ & $\begin{array}{l}\text { Ertugliflozin- } \\
\text { O- } \\
\text { glucuronidation }\end{array}$ & $\begin{array}{l}16 \mathrm{~h} \text { at } 15 \mathrm{mg} \\
\text { dose }\end{array}$ & $\begin{array}{c}5,15 \\
\text { peros }\end{array}$ & SGLT2 & $\begin{array}{c}44- \\
47\end{array}$ \\
\hline
\end{tabular}

Table 2: SGLT 1 and 2 drugs in the early phase of clinical trials for the treatment of DM

\begin{tabular}{|l|l|l|c|c|c|c|}
\hline Generic name & Pharmacodynamics & $\begin{array}{l}\text { Primary } \\
\text { metabolite (s) }\end{array}$ & $\begin{array}{c}\text { Half life } \\
(\mathbf{h})\end{array}$ & $\begin{array}{c}\text { Dosage } \\
(\mathbf{m g})\end{array}$ & $\begin{array}{c}\text { Clinical Trial } \\
\text { Phase }\end{array}$ & Ref \\
\hline Ipragliflozin & $\begin{array}{l}300 \mathrm{mg} / \text { day induced } \\
90 \mathrm{~g} \text { of glucose } \\
\text { excretion }\end{array}$ & $\begin{array}{l}\text { By } \\
\text { conjugation in } \\
\text { hepatocytes }\end{array}$ & 12 & 25,50 & Phase III & $35-37$ \\
\hline Tofogliflozin & $\begin{array}{l}\text { Dose-dependent } \\
\text { increase in glucose } \\
\text { excretion }\end{array}$ & Carboxylic & $5-6$ & 30 & Phase III & 38 \\
\hline
\end{tabular}




\begin{tabular}{|c|c|c|c|c|c|c|}
\hline Sotagliflozin & $\begin{array}{l}400 \mathrm{mg} / \text { day induced } \\
70.7 \mathrm{~g} \text { of glucose } \\
\text { excretion }\end{array}$ & $\begin{array}{l}\text { Sotagliflozin- } \\
\text { 3-O- } \\
\text { glucuronide }\end{array}$ & 29 & 300 & Phase III & $39-42$ \\
\hline Ertugliflozin & $\begin{array}{l}15 \mathrm{mg} / \text { day induced } \\
34 \mathrm{~g} \text { of glucose } \\
\text { excretion }\end{array}$ & $\begin{array}{l}\text { UGT1A9 and } \\
\text { UGT2B7- } \\
\text { mediated O- } \\
\text { glucuronidatio } \\
\text { n }\end{array}$ & 16 & 5,15 & Phase III & 43 \\
\hline Luseogliflozin & $\begin{array}{l}25 \mathrm{mg} / \text { day induced } \\
70.9 \mathrm{~g} \text { of glucose } \\
\text { excretion }\end{array}$ & $\begin{array}{l}\text { Metabolized } \\
\text { by CYP3A4/5 } \\
\text { UGT1A1 } \\
\end{array}$ & $9-13$ & $2.5,5$ & & 44 \\
\hline Remogliflozin & $\begin{array}{l}1000 \mathrm{mg} / \mathrm{day} \\
\text { induced } 130 \mathrm{mg} \text { of } \\
\text { glucose excretion }\end{array}$ & GSK279782 & $2-4$ & & Phase III & $45-48$ \\
\hline Velagliflozin & Unknown & $\begin{array}{l}\text { Velagliflozin } \\
\text {-glucuronide }\end{array}$ & Unknow & & Phase II & 49 \\
\hline Henagliflozin & $\begin{array}{l}20 \mathrm{mg} \text { day induced } \\
82 \mathrm{mg} \text { of glucose } \\
\text { excretion }\end{array}$ & $\begin{array}{l}\text { Henagliflozin- } \\
\text { glucuronide }\end{array}$ & & 10,20 & Phase I & 50 \\
\hline Bexagliflozin & Unknown & Unknown & Unknown & $5,10,20$ & Phase III & 51 \\
\hline Sergliflozin & & 10 & $1-1.5$ & & Discontinued & \\
\hline
\end{tabular}


Figure 1. Chemical structure of SGLT2 inhibitors that have been approved by the United States Food and Drug Administration and the European Medicines Agency

Figure 2A. Chemical structure of SGLT inhibitors that have not been approved by the United States Food and Drug Administration and the European Medicines Agency

Figure 2B. Chemical structure of SGLT inhibitors that have not been approved by the United States Food and Drug Administration and the European Medicines Agency 


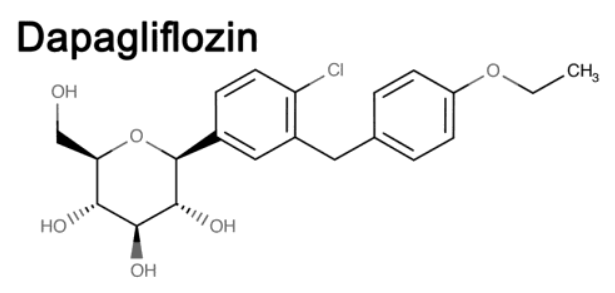

\section{Canagliflozin}<smiles>CCOc1ccc(Cc2cc([C@@H]3O[C@H](CO)[C@@H](O)[C@H](O)[C@H]3O)ccc2Cl)cc1</smiles>
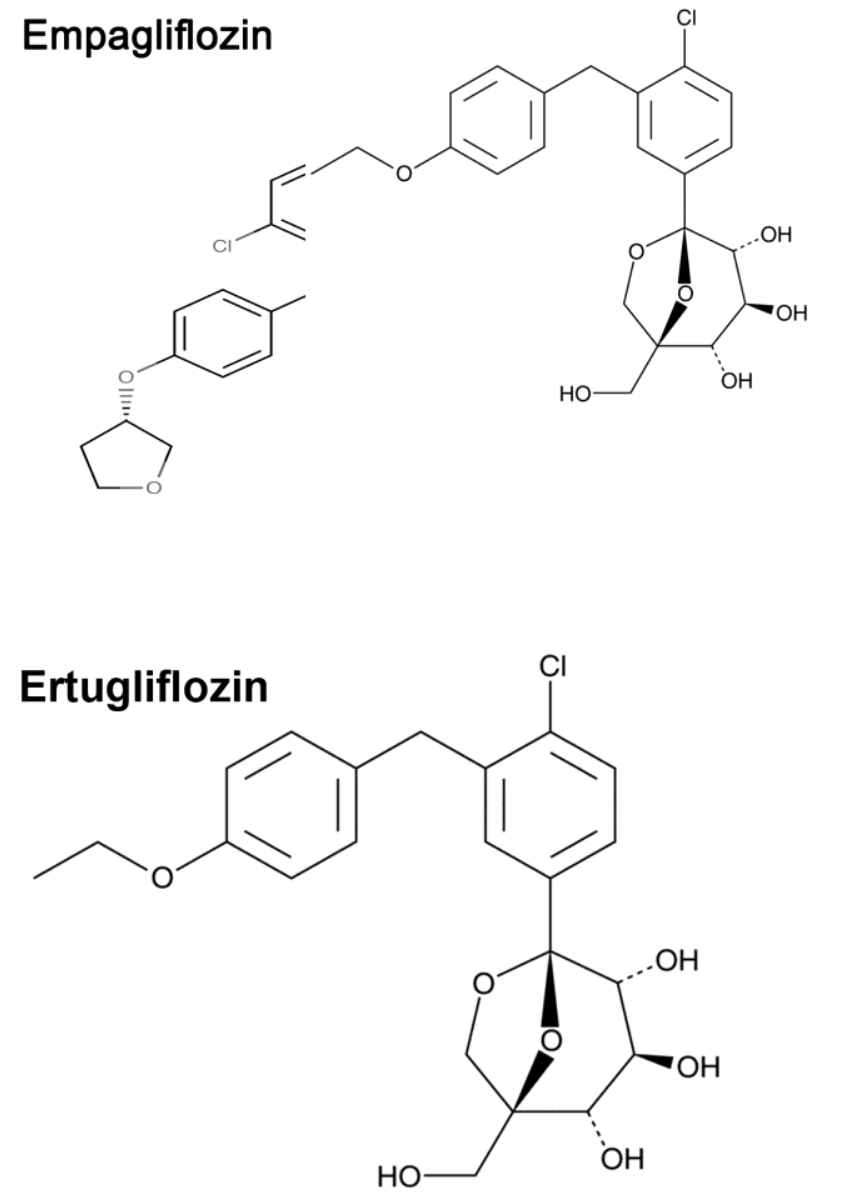

Figure 1 

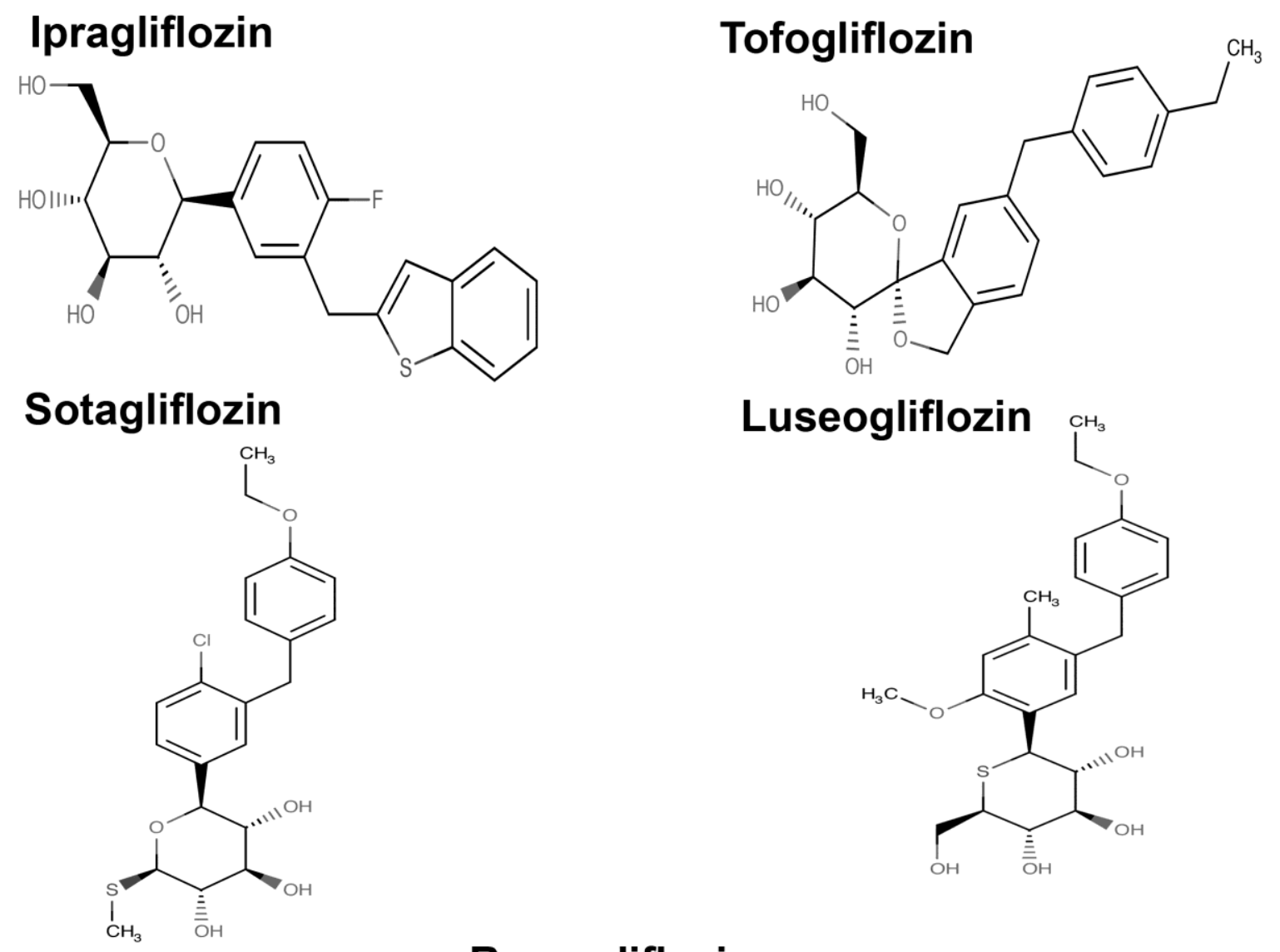

\section{Remogliflozin}<smiles>CCOC(=O)OC[C@H]1O[C@@H](Oc2nn(C(C)C)c(C)c2Cc2ccc(OC(C)C)cc2)[C@H](O)[C@@H](O)[C@@H]1O</smiles>

Figure 2A 
Velagliflozin

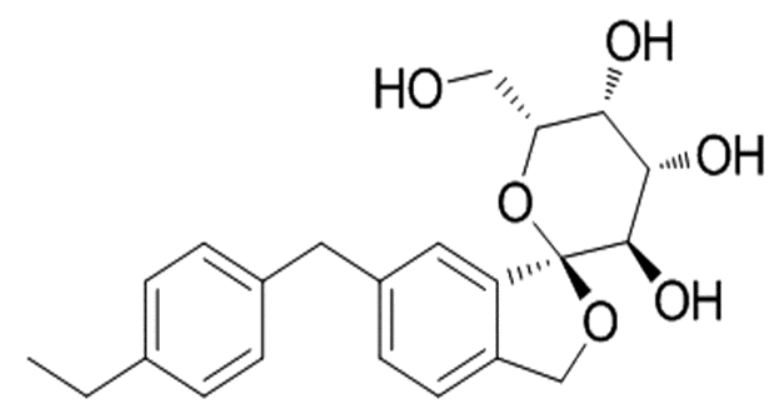

Bexagliflozin

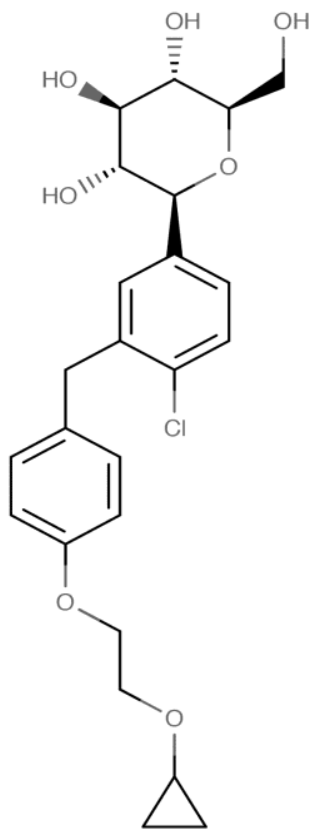

Henagliflozin

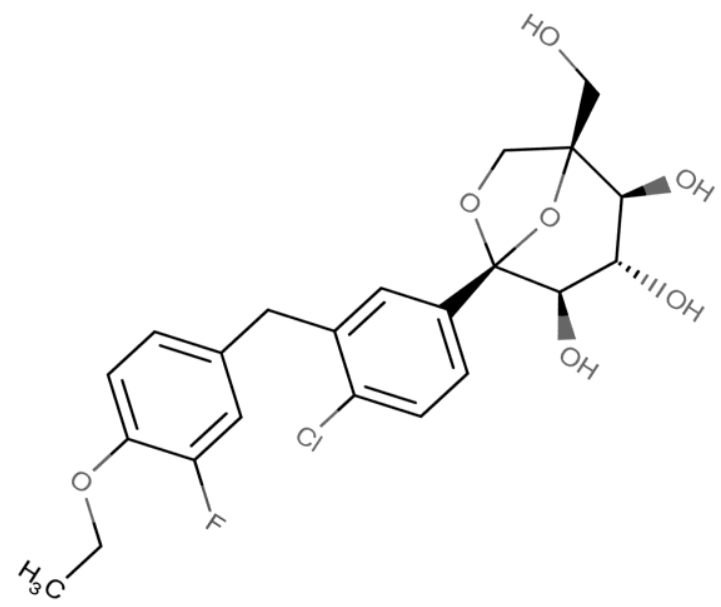

Licogliflozin<smiles>CCc1ccc([C@@H]2O[C@H](CO)[C@@H](O)[C@H](O)[C@H]2O)cc1Cc1ccc2c(c1)OCCO2</smiles>

Figure 2B 